\title{
EXPERIMENTAL TECHNIQUES IN CODE SWITCHING RESEARCH
}

\author{
Ondene van Dulm \\ University of Stellenbosch
}

This article discusses various experimental techniques which may be used to elicit data on code switching. A brief overview of the literature is followed by a description of the techniques used in a small-scale study of the structural aspects of intrasentential code switching between South African English (SAE) and Afrikaans. The aim of the small-scale study was to gather preliminary data which could be used to evaluate the empirical merit of a number of predictions for the structure of SAE-Afrikaans intrasentential code switching. In addition to the techniques used in the small-scale study, a number of adaptations and additions to be applied in the larger-scale study to follow are discussed. These improvements to the techniques are proposed on the basis of the results of the small-scale study, and take the relevant literature into account. The various techniques are discussed in terms of their ability to provide valid and reliable data which can be subjected to statistical analysis and which can fruitfully inform questions regarding the structure of intrasentential code switching. The benefits of research of this nature to language practitioners and to the field of linguistics are highlighted.

\section{INTRODUCTION}

Code switching entails the alternate use of two or more languages within a single utterance or conversation (Hoffmann, 1991:110). On the basis of the length and nature of the juxtaposed elements, one can distinguish between extrasentential, intersentential, and intrasentential code switching. Extrasentential code switching involves the insertion of a tag from one language into an utterance entirely in the other language (Hamers \& Blanc, 2000:259), such as in 'O nee hier's 'n paar goedjies, sorry' ('Oh no here are a few things, sorry'). Intersentential codeswitching involves switching at sentential boundaries (MacSwan, 1999:1), where one clause or sentence is in one language and the next clause or sentence is in the other, as in 'I love Horlicks maar hier's niks' ('I love Horlicks but there's none here'). Intrasentential code switching takes place within the clause boundary (Hamers \& Blanc, 2000:260), as in 'Ek weet nie of daar iets down my throat was nie' ('I don't know whether there was something down my throat'). Code switching between Afrikaans and South African English (SAE) is common among bilingual speakers of these two languages in South Africa, as is code switching between and among any of the languages spoken by bi- and multilingual individuals in the country. It is therefore essential that language practitioners be aware of this phenomenon, and recognise that it is more likely the result of fluent bilingualism, than of a lack of proficiency in one or more of the languages concerned (cf., in this regard, Adendorff, 1993; Kieswetter, 1995; Ncoko, Osman \& Cockcroft 2000). 
This article discusses experimental techniques for the elicitation of data on intrasentential code switching. Specifically, the techniques used in a small-scale study which was undertaken as part of a larger research project focused on structural aspects of intrasentential code switching between South African English (SAE) and Afrikaans, are discussed. In addition, a number of adaptations and additions to these techniques, developed on the basis of the results of the small-scale study and on a review of the literature, are discussed. These improvements on the techniques used in the initial study will be applied in the larger-scale study to follow.

The aim of the research project as a whole is a critical evaluation of the merit of a generalised account of intrasentential code switching, according to which the same principles accounting for monolingual phenomena also account for bilingual phenomena. Specifically, it is proposed that feature checking theory, a theory associated with minimalist syntax (cf. Chomsky, 1993; 1995; 2000), can account for the structure of intrasentential code switching between SAE and Afrikaans. On the basis of an analysis of certain structural differences between SAE and Afrikaans within the framework of feature checking theory, predictions were made for the structure of ten constructions in which SAE and Afrikaans are switched. These constructions included, among others, verb movement in focalisation structures, verb movement in topicalisation structures, yes-no questions, passive constructions, verb raising in adverbial constructions with verb-second (V2) in Afrikaans, and verb movement in that subordinate clauses.

Research on code switching traditionally makes use of spontaneously occurring naturalistic data (cf. Halmari, 1997; Myers-Scotton, 1993; Nortier, 1995; Treffers-Daller, 1994; among many others). However, the ability of such data to inform questions or predictions regarding specific constructions such as those mentioned above is limited, in that large amounts of spontaneous data may yield very few, if any, utterances containing the target constructions. The motivation for code switching research targeting such specific constructions lies in the possibility of applying syntactic theories developed to account for monolingual phenomena to code switching phenomena. In this way, the fields of syntax and sociolinguistics may begin to inform each other. For the purposes of such research, focused on particular code-switched constructions, it is necessary to turn to experimental techniques in order to generate data upon the basis of which the merit of specific predictions may be evaluated.

Toribio (2001: 406) mentions the restrictions related to naturalistic data, in that the linguistic performance of a speaker does not necessarily accurately reflect his/her underlying knowledge. There is also the problem of variability among speakers and communities, where corpora of naturalistic data often contain counter-examples to the particular constraint on code switching which is being posited (Toribio, 2001: 406). These limitations of naturalistic data, for the purposes of inquiry into the syntactic aspects of code switching, necessitate the use of experimental methodologies. In its most basic form, such experimental methodology involves judgments of well-formedness (or acceptability), similar to the grammaticality judgments often applied in the field of syntax to monolingual structures (cf. Schütze, 1996 for an informative exposition of the use of grammaticality and well-formedness judgments in linguistic research). Such a judgment task may, for example, require an informant to consider the sentences 'I like dogs' and 'I likes dogs' and label each as either 'grammatical' or 'ungrammatical'. As noted by Cornips \& Poletto (2005: 941), 'questions about the (un)grammaticality of syntactic features may provide insight into a speaker's competence far more readily than spontaneous speech data do'. Furthermore, the elicitation of wellformedness judgments opens a window on informants' reactions to sentence types that do not 
readily occur in corpora of naturalistic data (Cornips \& Poletto, 2005: 941). The use of intuitive data such as that generated by grammaticality or well-formedness judgments has a long history in linguistic research. Botha (1973: 174), for example, mentions the use of linguistic intuitions as empirical evidence against which predictions of linguistic hypotheses may be tested. As noted by Henry (2005: 1617), it is ideal if intuition-based data in linguistic research can be supported by corpus data as far as this is possible.

With regard to the use of well-formedness judgments, Sorace (1993) discusses the various types of responses that may be required in a well-formedness judgment task. Much linguistic research is based on absolute judgments, where informants are required to assign a category to a given construction, typically choosing one of two categories, e.g. acceptable or unacceptable. A shortcoming of such absolute judgments is that the informant's response is constrained by the categories available, and possible differences among members of a particular category cannot be indicated. For example, in terms of well-formedness, a sentence which seems to the informant to be vaguely problematic but almost acceptable is placed in the same category (i.e., 'ill-formed' or 'unacceptable') as one which is grossly ungrammatical in the informant's opinion. The use of relative judgments overcomes this problem, where an informant is required to judge the relative well-formedness of a sentence in relation to one or more other sentences (Sorace, 1993: 398). For example, an informant may be required to rank a set of three or more sentences in terms of relative well-formedness. A further improvement on this technique is the application of magnitude estimation, by which an informant associates a numerical judgment with a stimulus, i.e., the sentence to be judged. By means of the magnitude estimation technique, the researcher obtains information on degrees of wellformedness, and the data can be statistically analysed in meaningful ways. (Magnitude estimation will be discussed in detail in section 2.2 below.)

An example of the use of sentence judgment data in code switching research can be found in MacSwan (1999). In his study of the grammatical aspects of intrasentential code switching between Spanish and Nahuatl, MacSwan (1999) used both naturally occurring data and sentence judgment data. Sentence judgments were carried out by fluently bilingual consultants, who were introduced by the researcher to the phenomenon of code switching, and given an example of what the researcher considered to be an 'extremely bad' codeswitched construction which they could use as a prototypical ill-formed sentence (MacSwan, 1999: 103). The consultants typically wrote down and read aloud the sentences to be judged, discussing some cases at length, and were required to give every sentence a ranking of wellor ill-formedness, in relation to the prototypical worst case provided.

Besides judgments of well-formedness, there are a number of other techniques which may tap bilingual speakers' linguistic intuitions about code-switched constructions. In her study of the syntactic regularities underlying Spanish-English code switching, Toribio (2001) used, firstly, a reading task. In the reading task, informants were required to read aloud one fairytale containing 'grammatically unacceptable' code switching, and a second fairytale containing 'well-formed code-switched sentences' (Toribio, 2001: 408). Informants were then required to answer questions relating to the 'readability, comprehension, enjoyability, and grammatical form' of the passages (Toribio, 2001: 408). A further task in Toribio's (2001) study was a verbal recounting task, where informants were required to retell the ending of one of the stories that had been read. In a final task, informants wrote the story of a third fairytale, depicted by a series of pictures, having been instructed to mix Spanish and English in their writing of the narrative (Toribio, 2001: 408). Toribio (2001: 433) concludes that these 
methodologies are 'valid and informative' techniques in the study of the linguistic competence underlying code switching.

In section 2 below, a description is given of the experimental techniques used in the smallscale study of intrasentential code switching between SAE and Afrikaans. The sociolinguistic background of the informants is briefly set out in section 2.1 . The tasks completed by these informants are described in section 2.2, 2.4 and 2.6. On the basis of the performance of the informants in these tasks, and in light of the techniques applied in the literature, a number of adaptations and additions have been devised for use in the larger-scale study. These are set out in sections $2.3,2.5$, and 2.7.

\section{EXPERIMENTAL TECHNIQUES}

\subsection{Informants}

The informants were four 22-year-old white male engineering students at Stellenbosch University, fluent in standard South African English and standard Afrikaans, as assessed by themselves and informally by the researcher. It was assumed that such adequate levels of proficiency in both languages are required in order for code switching to occur on a regular basis and in accordance with regular patterns. Speakers of the mixed code often referred to as 'Cape Afrikaans' or 'Kaaps', a code spoken mainly by the coloured community in the Western Cape, in which there is convergence between English and Afrikaans (cf. McCormick, 1995, 2002; Stone, 1995) were excluded from consideration as informants. Code switched utterances and well-formedness judgments of speakers of this non-standard variety may differ considerably from those of speakers bilingual in standard SAE and standard Afrikaans, due to the influence of lexical and structural aspects of the mixed code. Two of the informants were English mother-tongue speakers, and two Afrikaans, in order that the sample be adequately representative of the code switching population in general, and so that an indication could be obtained, on the basis of the results of the small-scale study, as to whether the larger-scale study should include mother tongue speakers of both groups or just one of the groups. Results revealed no significant difference between the two groups. Informants were required to exhibit a neutral or positive attitude toward code switching, as a negative attitude may confound the validity of results (cf. Pfaff, 1979 which makes the point that speakers have been known to reject as impossible the sentences they themselves have uttered). Attitude toward code switching was evaluated by means of a screening questionnaire, in which informants were asked whether they viewed the language use reflected by a set of utterances in which SAE and Afrikaans are mixed in a positive, neutral or negative light.

\subsection{Well-formedness judgements}

In the small-scale study reported here, informants were required to carry out two wellformedness judgment tasks. The first task required informants to make judgments of the relative well-formedness of visually presented sentence pairs, and the second of auditorily presented utterance pairs. In each pair, one construction was that predicted to be judged wellformed and the other that predicted to be judged ill-formed, the aim being to ascertain the extent to which informants preferred the constructions predicted by the syntactic analyses to be well-formed. The order of the predicted well-formed and predicted ill-formed constructions was randomised throughout. Alternate informants judged alternating lists of 
visually and auditorily presented items. In other words, one informant judged list 1 visually and list 2 auditorily, while the next judged list 2 visually and list 1 auditorily. Each judgment task contained 42 sentence/utterance pairs to be judged, comprising 4 pairs targeting each of the ten constructions for which predictions had been made, and including two practice items. The items were randomised in terms of the construction targeted. Both judgment tasks were web-based, requiring the informant to click on the sentence or utterance s/he considered 'more acceptable'. Informants were instructed to ignore what they thought might be 'right' or 'wrong', and to select on the basis of which sentence/utterance they would be more likely to deem acceptable in everyday bilingual conversation. In this way, the attention was shifted away from grammaticality, often a confounding factor in well-formedness judgments (cf. Schütze, 1996). In the construction of the sentences and utterances to be judged, the relative frequency of words in everyday conversation was borne in mind, as was the cognate status of words, and words which are homophonic in the two languages were avoided. For purposes of illustration, two sentence pairs are given below, the first targeting focalisation constructions and the second yes-no questions (the construction predicted to be well-formed is given first in these examples).

(1) Volgende maand I fly to London. ('Next month I fly to London.') Volgende maand fly I to London.

(2) Does the child read daardie soort boeke? ('Does the child read those kinds of books?') Read the child daardie soort boeke?

Informants performed these well-formedness tasks without problems, and the results indicated that judgments were in accordance with the predictions for eight of the ten constructions, and against predictions for two of the constructions. Schütze (1996: 2) notes the advantages of well-formedness judgments such as those outlined here, for example that they allow one to examine sentences that seldom occur in spontaneous speech, and that they allow one to gather negative evidence. However, Schütze (1996: 4) also notes the lack of standard experimental control techniques in many linguistic studies utilising judgments of grammaticality or well-formedness. In the absence of such control, the conclusions that can legitimately be based on the results obtained are limited, as are the statistical analyses that can be applied to the results. A technique that improves the situation is that of magnitude estimation, which will be applied in the larger-scale study in order to enable finer-grained analyses of what informants regard as well- and ill-formed.

\subsection{Magnitude estimation}

Chomsky (1975: 131) suggests that an adequate linguistic theory has to recognise 'degrees of grammaticalness'. As linguistic theories tend to be based on linguists' opinions regarding the grammaticality or well-formedness of particular constructions, a formal theory of gradience in well-formedness judgments is desirable (Keller, 2000: 19). The use of magnitude estimation (ME) in linguistic experimentation addresses this issue, by making it possible to treat well-formedness as a continuum, and to measure directly the differences in terms of well-formedness between or among a number of constructions (Keller, 2000: 38). The technique of ME is traditionally used in the field of psychophysics in the measurement of people's perception of sensory stimuli, e.g., the relative brightness of each light stimulus in a set of light stimuli, or the relative loudness of each sound stimulus in a set of sound stimuli (cf. Stevens, 1975). The technique of ME was introduced to the realm of the social sciences by Lodge (1981). ME requires an informant to assign a numerical value to a given stimulus. 
This initial stimulus acts as the reference, and the informant assigns numerical values to subsequent stimuli in relation to that of the reference. A relative scaling of the stimuli is thus achieved. Besides the assigning of numerical values, other response modalities may also be used, such as varying the pressure of hand grip on a rubber handle, adjusting the sound pressure level of a tone, or drawing lines of varying lengths in response to stimuli (cf. Stevens, 1975; Lodge, 1981). By utilising more than one response modality for a particular set of stimuli, it is possible to validate the scales obtained by cross-modality matching (cf. Lodge, 1981).

A number of studies in the field of linguistics have successfully applied the ME technique in gathering data to inform questions on both monolingual (cf. Bard, Robertson and Sorace, 1996; Keller, 2000) and bilingual phenomena (cf. Sorace, 1993; Pandur, 2004). In the largerscale study to be undertaken to gather data to inform the predictions for the structure of SAEAfrikaans code switching, ME will be used in a separate task to the judgment tasks described in section 2.1 above. Firstly, informants will be required to complete a training exercise. In the training exercise, they will assign numerical values to a series of lines (one reference line of $50 \mathrm{~mm}$ with a pre-assigned value of 50, plus 10 other lines of varying lengths), and then draw lines to represent a series of numbers (one reference number of 50 represented by a line of $50 \mathrm{~mm}$, plus 10 other numbers). It has been found that, in such line length estimation tasks, people produce a 1:1 response; in other words, a $45^{\circ}$ angle is obtained if one plots the logs of the mean of responses against those of the actual line lengths (cf. Stevens, 1975). This makes line length estimation a good training exercise in experiments which apply ME to social stimuli (Lodge, 1981: 8). Furthermore, this training exercise establishes a baseline for each informant or group of informants, to which their judgments of the experimental stimuli (in this case, well-formedness judgments for code-switched sentences) can be compared. The use of two response modalities, namely numerical estimation and line production, provides further control over the experiment, as cross-modality validation is possible (cf. Bard et al., 1996). The second part of the ME task will require informants to carry out numerical estimation and line production in response to sets of sentences. There will be two sets of eight sentences for each prediction to be investigated in the larger-scale study. Each set of sentences will contain two code-switched sentences predicted to be regarded as well-formed, two code-switched sentences predicted to be regarded as ill-formed, one grammatical and one ungrammatical monolingual SAE sentence, and one grammatical and one ungrammatical monolingual Afrikaans sentence. The sentences will all be of a similar construction (that which is targeted by the particular prediction), and each of the monolingual sentences will express the same proposition as one of the code-switched sentences. The set of sentences in (3), targeting the predictions regarding yes-no questions, serves as an illustration.

$$
\begin{aligned}
& \text { Does the child read daardie soort boeke? } \\
& \text { Read the child daardie soort boeke? } \\
& \text { Lees die kind daardie soort boeke? } \\
& \text { Does read the child those kinds of books? } \\
& \text { Slaap jou baba sussie on that bed? } \\
& \text { Doen jou babasussie slaap on that bed? } \\
& \text { Sleeps your baby sister on that bed? } \\
& \text { code-switched, predicted well-formed } \\
& \text { code-switched,predicted ill-formed } \\
& \text { monolingual Afrikaans grammatical } \\
& \text { monolingual SAE ungrammatical } \\
& \text { code-switched, predicted well-formed } \\
& \text { code-switched,predicted ill-formed } \\
& \text { monolingual SAE grammatical } \\
& \text { Doen jou babasussie slaap op daardie bed? monolingual Afrikaans ungrammatical }
\end{aligned}
$$

The relatively small size of each set of sentences, each with its own reference and each targeting one construction type, makes the task easier for the informants (cf. Pandur, 2004: 43). The reference sentence for each set will vary randomly, i.e., in a particular set, any one 
of the sentence types may be presented first as the reference, with a pre-assigned number and line length in terms of its degree of well-formedness. The use of ME as described for this task will yield scales of the relative well-formedness of the constructions concerned. In addition, it will be possible to draw comparisons between the data on the code-switched constructions and the monolingual constructions. The data from such a ME task is thus more informative than that gathered by the relative well-formedness judgments described in 2.1 alone, and more in-depth statistical analyses are also possible.

\section{$2.4 \quad$ Sentence completion}

The second task carried out by informants in the small-scale study of SAE-Afrikaans intrasentential code switching was a sentence completion task, also presented in a web-based format. In this task, the informant was presented with one part of a sentence, and was required to select the most suitable of three possible options for the other part of the sentence. Of the three possibilities, one reflected the structure predicted to be considered well-formed, a second the structure predicted to be considered ill-formed, and the third a syntactic foil, in which the word order was clearly ungrammatical. Once again, the sentences were constructed specifically to target the predictions made, and there was a total of 42 items in the task. The sentence completion task yielded similar results to those found in the well-formedness judgment tasks. In the illustrative example items below, the first option is the predicted wellformed structure, the second the predicted ill-formed structure, and the third the syntactic foil. The item in (4) targets verb movement in that subordinate clauses, while that in (5) targets topicalisation constructions.

(4) John said that the

horses resies jaag.

horses jaag resies.

resies horses jaag.

('John said that the horses run races.')

$$
\begin{aligned}
& \text { Kyk die seilboot daar op die baai. Daardie boot } \text { I find beautiful } \\
& \text { find I beautiful } \\
& \text { beautiful find I }
\end{aligned}
$$

('Look at that sailing yacht on the bay. That boat I find beautiful.')

Informants in the small-scale study found this task perfectly manageable, and results were similar to those obtained in the well-formdness judgment tasks. However, it should be pointed out that the sentence completion task described here requires the same type of judgment as do the well-formedness judgment tasks. The only difference is that there is a third possibility, but this third option is clearly ungrammatical, and so is unlikely to be considered well-formed. The sentence completion task will therefore be replaced by a sentence construction task in the larger-scale study.

\subsection{Sentence construction}

The sentence construction task in the larger-scale study will be presented in the form of a drag-and-drop activity on a PC, where the informant will have a number of sentence fragments which s/he must piece together to create a well-formed sentence. Informants will be instructed to utilise all the given sentence fragments. The order of sentence fragment presentation will be randomised in terms of the predicted well-formed word order for each 
construction. In such a task, the informant has more freedom to construct a sentence with whatever word order s/he considers well-formed, rather than being restricted to two or three options offered by the researcher. Data from such a task may give a more reliable reflection of what informants actually consider to be well-formed, rather than simply indicating which of a number of researcher-constructed forms are preferred. In order to illustrate how the task will be presented to informants, two example items are given below, both targeting verb raising in adverbial constructions with V2 in Afrikaans.
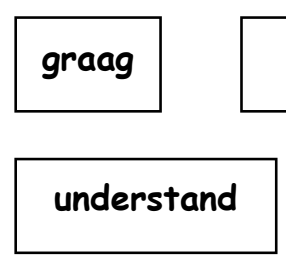
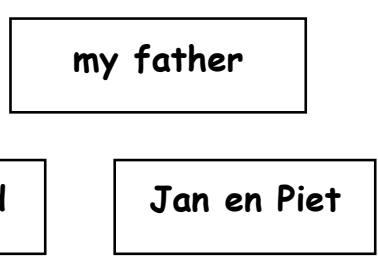
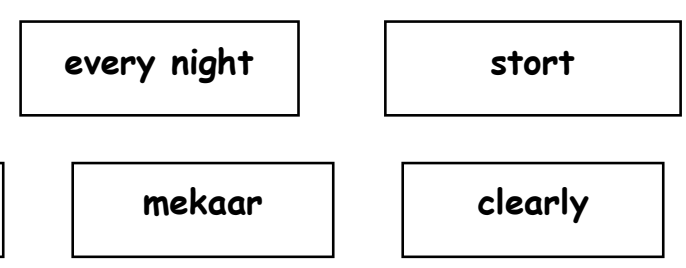

\subsection{Picture description}

The third experimental technique used in the small-scale study required informants to carry out a picture description task. In this task, the informant was shown a photograph to describe. At the bottom of the photograph, the beginning of a sentence was presented in either SAE or Afrikaans, and the informant was instructed to use the other language somewhere in his/her completion of the sentence, leaving the informant a choice as to where to switch languages. For example, the informant was shown a picture of a woman playing Lego with two boys and building puzzles with two girls, and given the sentence fragment 'Met die seuns...', the target being the SVO structure 'the woman plays Lego'. In such a focalisation construction, the Afrikaans structure would be VSO, as in 'speel die vrou Lego'. The purpose of providing the beginning of the sentence was to guide the response to an approximation of the target, the target in each case reflecting one of the predicted structures. A total of 42 pictures were presented, comprising two practice items and four pictures per prediction.

In the large majority of cases (approximately 75\%), the target utterances were not produced by informants in response to the picture description task items. For example, in response to the item above, a typical response was 'sit daar also a few girls'. Although the structural aspects of such responses may in many cases be fruitfully analysed within the theoretical framework adopted by the research, such data do not directly inform the predictions concerned. It appears that the sentence fragment given as an introduction to each target structure did not reliably lead the informant into producing the target structure. In order to overcome the shortcomings of the picture description task, the larger-scale study will employ a video clip description task instead.

\subsection{Video clip description}

In the video clip description task, informants will be required to view a 5-10 second video clip of an event taking place. The clips will be available at a click on a PC media player, and the informant will be able to view each clip as many times as s/he requires. An introductory text will appear below each video clip. In this introductory text, a number of sentences containing intrasentential code switching between SAE and Afrikaans will provide the background to lead the informant into producing the target utterance, the final sentence being incomplete. After reading the introductory text, the informant will describe the event by 
completing the final sentence. The informant will be instructed to use both languages in the completion of the sentence, but will be free to produce any utterance s/he may wish to describe the video clip. An example of an item in this task may be a video clip of a woman putting open cheese sandwiches under the grill. The introductory text may be: 'Hierdie vrou moet vir the children kosmaak. She wants to make hulle gunsteling. Sy weet dat die kinders ...,' where the target is 'love toasted cheese'. This remains the most spontaneous task of the battery, yielding data over which the researcher has the least amount of control. The use of the video clips and the longer code-switched introductory text, however, is an attempt to mould responses to a greater degree than was possible in the picture description task, and so to gather a greater proportion of data which can directly inform the predictions.

\section{CONCLUDING REMARKS}

Various techniques for gathering experimental data on code switching have been described in this article. The techniques represent a wide range of possibilities in terms of (i) the time required for informants to carry out the tasks (compare, for example, the relative wellformedness judgments to the ME task with its training exercise); (ii) the amount of time and effort required by the researcher for task preparation (compare, for example, the making of video clips to the taking of photographs for description); (iii) the extent to which the data may inform specific questions regarding the structure of code-switched sentences (compare, for example, the data gathered by the ME task to that gathered by picture description); and (iv) the amount of control the researcher has over the informants' responses (compare, for example, the well-formedness judgments with two options to the sentence construction task with a number of options). The researcher interested in the structural aspects of code switching, and wishing to go beyond naturalistic data, can select from an array of these and other techniques which have been successfully applied in the field of linguistics. It appears that a battery of tried and tested experimental techniques may yield reliable and valid data which can inform questions regarding the structure of intrasentential code switching. Research of this nature may lead to a greater understanding of the cognitive mechanisms underlying code switching, which may be of benefit to language practitioners, such as teachers dealing with bilingual children in the classroom. Furthermore, such research strengthens the link between various fields of linguistics, such as syntax, sociolinguistics and psycholinguistics, and illustrates how these fields may inform one another.

\section{ACKNOWLEDGEMENT}

This material is based upon work supported by the National Research Foundation under grant number NRF GUN 2069846. Any opinion, findings and conclusions or recommendations expressed in this material are those of the author and do not necessarily reflect the views of the National Research Foundation.

\section{REFERENCES}

ADENDORFF, R. 1993. Code-switching amongst Zulu-speaking teachers and their pupils: Its functions and implications for teacher education. Southern African Journal of Applied Language Studies, 2(1): 3-26. 
BARD, EG, D ROBERTSON \& A SORACE. 1996. Magnitude estimation of linguistic acceptability. Language, 72(1):32-68.

CHOMSKY, N. 1975. The logical structure of linguistic theory. New York: Plenum Press.

CHOMSKY, N. 1993. A minimalist program for linguistic theory. In Hale, K \&. SJ Keyser (eds), The view from building 20. Essays in linguistics in honor of Sylvain Bromberger. Cambridge, Massachusetts: MIT Press, 1-52.

CHOMSKY, N. 1995. The minimalist program. Cambridge, Massachusetts \& London: MIT Press.

CHOMSKY, N. 2000. Minimalist inquiries: The framework. In Martin, R, D Michaels \& J Uriagereka (eds), Step by step. Essays on minimalist syntax in honor of Howard Lasnik. Cambridge, Massachusetts \& London: MIT Press, 89-155.

CORNIPS, L \& C POLETTO. 2005. On standardising syntactic elicitation techniques (Part 1). Lingua, 115: 939-957.

HALMARI, H. 1997 Government and codeswitching: Explaining American Finnish. Amsterdam: Benjamins.

HAMERS, JF \& HA Blanc. 2000. Bilinguality and bilingualism. Cambridge: CUP.

HOFFMANN, C. 1991. An introduction to bilingualism. London: Longman.

HENRY, A. 2005. Non-standard dialects and linguistic data. Lingua, 115:1599-1617.

KELLER, F. 2000. Gradience in grammar. Experimental and computational aspects of degrees of grammaticality. $\mathrm{PhD}$ dissertation, University of Edinburgh. http://homepages.inf.ed.ac.uk/keller/papers/phd.pdf (Accessed 25 May 2005)

KIESWETTER, A. 1995. Code-switching among African high school pupils. University of the Witwatersrand Occasional Papers in Linguistics 1.

LODGE, M. 1981. Magnitude scaling. Quantitative measurement of opinions. Beverley Hills \& London: Sage Publications.

MACSWAN, J. 1999. A minimalist approach to intrasentential code switching. New York \& London: Garland Publishing.

MCCORMICK, K. 1995. Code-switching, code-mixing and convergence in Cape Town. In Mesthrie, R (ed.),1995. Language and social history. Cape Town \& Johannesburg: David Philip Publishers, 193-208.

MCCORMICK, K. 2002. Language in Cape Town's District Six. Oxford: Oxford University Press.

MYERS-SCOTTON, C. 1993. Duelling languages. Oxford: Clarendon Press. 
NCOKO, SOS, R Osman \& K Cockroft. 2000. Codeswitching among multilingual learners in primary schools in South Africa: An exploratory study. International Journal of Bilingual Education and Bilingualism, 3(4): 225-241.

NORTIER, JM. 1995. Code switching in Moroccan Arabic/Dutch vs. Moroccan Arabic/French language contact. International Journal of the Sociology of Language, 112:81-95.

PANDUR, Z. 2004. Absolute and relative grammaticality judgments of speakers of English as a first and second language. Exploring the edges of the core domains. $\mathrm{PhD}$ dissertation, University of Amsterdam. http://www.rhesa.com/zsanett/mathesis.pdf (Accessed 25 May 2005)

PFAFF, C. 1979. Constraints on language mixing: Intrasentential code-switching and borrowing in Spanish/English. Language, 55: 291-318.

SCHÜTZE, CT. 1996. The empirical base of linguistics. Grammaticality judgments and linguistic methodology. Chicago \& London: University of Chicago Press.

SORACE, A. 1996. The use of acceptability judgments in second language acquisition research. In Ritchie, WC \& TK Bhatia (eds), Handbook of second language acquisition. San Diego: Academic Press, 375-409.

STEVENS, SS. 1975. Psychophysics. Introduction to its perceptual, neural, and social prospects. New York: John Wiley \& Sons.

STONE, G. 1995. The lexicon and sociolinguistic codes of the working-class Afrikaansspeaking Cape Peninsula coloured community. In Mesthrie R (ed.), Language and social history. Studies in South African sociolinguistics. Cape Town \& Johannesburg: David Phillips, 277-290.

TORIBIO, AJ. 2001. Accessing bilingual code-switching competence. International Journal of Bilingualism, 5(4):403-436.

TREFFERS-DALLER, J. 1994. Mixing two languages. French-Dutch contact in a comparative perspective. Berlin \& New York: Mouton de Gruyter.

\section{Biographic Note}

Ondene van Dulm is a lecturer in the Department of General Linguistics at Stellenbosch University. Her doctoral research focuses on structural aspects of English-Afrikaans intrasentential code switching. E-mail: ovd@sun.ac.za. 